\title{
Keamanan dan Kerahasiaan Berkas Rekam Medis di RSUD Dr. Soehadi Prijonegoro Sragen
}

\author{
Tazia Intan Prasasti ${ }^{1}$, Dian Budi Santoso ${ }^{2}$ \\ Diploma III Rekam Medis Sekolah Vokasi UGM ${ }^{1,2}$ \\ tazia2017@yahoo.com ${ }^{1}$, dianbudisantoso@gmail.com²
}

\begin{abstract}
ABSTRAK
Latar Belakang: Keamanan dan kerahasiaan merupakan faktor yang sangat penting dalam pengelolaan berkas rekam medis. Keamanan dan kerahasiaan rekam medis di RSUD dr. Soehadi Prijonegoro Sragen belum terjaga. Pasien yang akan konsultasi ke poliklinik lain membawa berkas rekam medisnya sendiri. Masih ada petugas selain petugas rekam medis yang keluar masuk ruang filing sehingga informasi dalam berkas rekam medis berpotensi jatuh pada pihak yang tidak berhak.

Tujuan: Mengetahui keamanan dan kerahasiaan rekam medis di Rumah Sakit Umum Daerah dr. Soehadi Prijonegoro Sragen.

Metode: Jenis penelitian yang digunakan adalah penelitian kualitatif dengan pendekatan fenomenologi. Teknik pengumpulan data yang digunakan pada penelitian ini adalah wawancara dan observasi. Subjek penelitian yaitu 1 orang kepala instalasi rekam medis dan 3 orang petugas rekam medis. Objek penelitian adalah berkas rekam medis.

Hasil: Tinta yang digunakan sudah seragam, jelas dan rata. Kertas yang digunakan adalah HVS dengan ukuran A4 berat 70 gram. Map yang digunakan dari bahan karton. Tersedia alat pemadam kebakaran dan rutin dilakukan pengecekan sekring. Ruang filing tidak tahan gempa dan pemeliharaan kebersihan masih kurang. Masih ada pihak lain yang masuk ruang filing. Pasien membawa sendiri berkas rekam medisnya.

Kesimpulan: Keamanan rekam medis ditinjau dari faktor internal menunjukkan semua komponen sudah aman yaitu tinta, kertas, dan map. Ditinjau dari faktor eksternal, semua komponen belum aman yaitu pihak lain yang tidak berkewenangan, bencana, debu, serta serangga dan hama perusak lainnya. Kerahasiaan rekam medis belum terjaga karena pasien masih membawa sendiri berkas rekam medisnya.
\end{abstract}

Kata Kunci: Keamanan, Kerahasiaan, Berkas Rekam Medis.

\begin{abstract}
Background: The security and confidentiality of medical record are very important factor in the medical record. The security and confidentiality of the medical record in RSUD dr. Soehadi Prijonegoro Sragen can not guaranteed. Patients who will be consulting to other clinics bring medical record file itself. There are other officers who are not legitimate can pass through freely. It caused information in the medical record may be read by other that are not legitimates.

Objective : To identify the security and confidentiality of the medical record in RSUD dr. Soehadi Prijonegoro Sragen.

Methods : The is qualitative study with phenomenology approach. Data collection technique in this study is interviews and observation. The subject is 1 the head of the installation medical record and 3 medical record clerk. The object of this research is the medical record file.

Result : The ink used been clear and flat. The paper is HVS with A4 size weight 70 grams. The folder that is used from the carton. Available fire extinguishers and routinely checking fuse. The filing room not earthquake proof and the maintenance of cleanliness are still lacking. There are another parties enter the filing room. Patients bring their own medical record file.

Conclusion : Medical record security is assessed in terms of the internal and external factors. The confidentiality of medical record is not secure because patients still bring their own medical record file..
\end{abstract}

Keywords : security, confidentiality, medical record 


\section{PENDAHULUAN}

Rekam medis adalah catatan tentang siapa, apa, dimana, dan bagaimana perawatan pasien selama di rumah sakit (Rustiyanto, 2009). Salah satu aspek kegunaan rekam medis yaitu aspek dokumentasi yaitu rekam medis mengandung informasi penting yang bermanfaat untuk berbagai pihak. Rekam medis berisi data mengenai kesehatan masa lalu dan masa kini dan berisi catatan profesional kesehatan mengenai keadaan pasien saat ini dalam bentuk penemuan fisik, hasil prosedur diagnosa dan terapi serta respon pasien (Huffman, 1994).

Penyelenggaraan rekam medis saat ini masih belum sempurna, rekam medis masih dianggap tidak terlalu penting oleh sebagian pelayanan kesehatan padahal kualitas rekam medis merupakan cerminan dari baik atau buruknya pelayanan kesehatan. Rekam medis merupakan salah satu data yang dapat digunakan dalam pembuktian kasus malpraktek di pengadilan. Rekam medis juga sebagai salah satu dokumentasi keadaan pasien dan isi rekam medis merupakan rahasia kedokteran yang harus dijaga kerahasiannya oleh setiap tenaga kesehatan (Hatta, 2010).

Pembuatan rekam medis bertujuan untuk mendapatkan data dari pasien mengenai riwayat kesehatan, riwayat penyakit dimasa lalu dan sekarang selain itu juga pengobatan yang telah diberikan kepada pasien sebagai upaya meningkatkan pelayanan kesehatan. Informasi tentang identitas, diagnosis, riwayat penyakit, riwayat pemeriksaan, dan riwayat pengobatan pasien harus dijaga kerahasiaannya oleh dokter, dokter gigi, tenaga kesehatan tertentu, petugas pengelola, dan pimpinan sarana pelayanan kesehatan. Pimpinan sarana kesehatan bertanggung jawab atas hilang, rusak, pemalsuan dan atau penggunaan oleh orang atau badan yang tidak berhak terhadap rekam medis (Hatta, 2010).

Kesehatan

Berdasarkan Peraturan Menteri

269/MENKES/PER/III/2008 tentang

rekam medis, pasal 10 ayat (1) bahwa informasi tentang identitas, diagnosis, riwayat penyakit, riwayat pemeriksaan dan riwayat pengobatan pasien harus dijaga kerahasiaannya oleh dokter, dokter gigi, tenaga kesehatan tertentu, petugas pengelola dan pimpinan sarana pelayanan kesehatan.

Berdasarkan studi pendahuluan yang dilakukan peneliti pada tanggal 6 Desember 2016 di Rumah Sakit Umum Daerah dr. Soehadi Prijonegoro Sragen, didapatkan hasil wawancara dengan salah satu petugas rekam medis Rumah Sakit Umum Daerah dr. Soehadi Prijonegoro Sragen bahwa pelaksanaan keamanan berkas rekam medis di rumah sakit ini masih kurang. Pertama, pintu filing memang selalu dikunci namun kunci pintu ruang filing tersebut belum aman. Hal tersebut akan mengakibatkan orang lain atau yang tidak berkepentingan dengan mudah masuk ke ruang filing karena sangat mudah untuk dibuka oleh orang lain. Kedua, ketika ada pasien dirujuk ke poliklinik lain atau ke fasilitas penunjang seperti laboratorium dan radilogi, berkas rekam medis dibawa sendiri oleh pasien ke poliklinik atau fasilitas penunjang yang dituju. Seharusnya rumah sakit bertanggung jawab dalam hal melindungi informasi yang ada di dalam catatan medis yang bertujuan untuk mencegah agar tidak dibaca dan dipergunakan oleh orang yang tidak semestinya mendapatkan informasi tersebut. Selain melakukan wawancara, peneliti juga melakukan observasi. Didapatkan hasil masih sering ada petugas selain petugas rekam medis yang keluar masuk ruang penyimpanan berkas rekam medis tanpa alasan yang tepat.. Hal ini mengakibatkan informasi di dalam berkas rekam medis dapat terbaca oleh orang lain dan hal tersebut tidak sesuai dengan standar keamanan dan kerahasiaan berkas rekam medis.

Tujuan dari penelitian ini adalah untuk mengetahui aspek keamanan dan kerahasiaan rekam medis di Rumah Sakit Umum Daerah dr. Soehadi Prijonegoro Sragen.

\section{METODE PENELITIAN}

Jenis penelitian yang digunakan dalam penelitian ini adalah kualitatif dengan pendekatan fenomenologi. Teknik 
pengumpulan data yang digunakan pada penelitian ini adalah wawancara dan observasi. Instrumen penelitian yang digunakan adalah pedoman wawancara dan check list observasi. Subjek penelitian adalah kepala instalasi rekam medis dan 3 orang petugas rekam medis. Objek penelitian adalah berkas rekam medis.

\section{HASIL DAN PEMBAHASAN}

Aspek kerahasiaan dan keamanan berkas rekam medis merupakan hal yang wajib diperhatikan dan dipenuhi oleh fasilitas pelayanan kesehatan. Aspek kerahasiaan dan keamanan berkas rekam medis dalam penelitian ini diilustrasikan dalam gambar 1 .

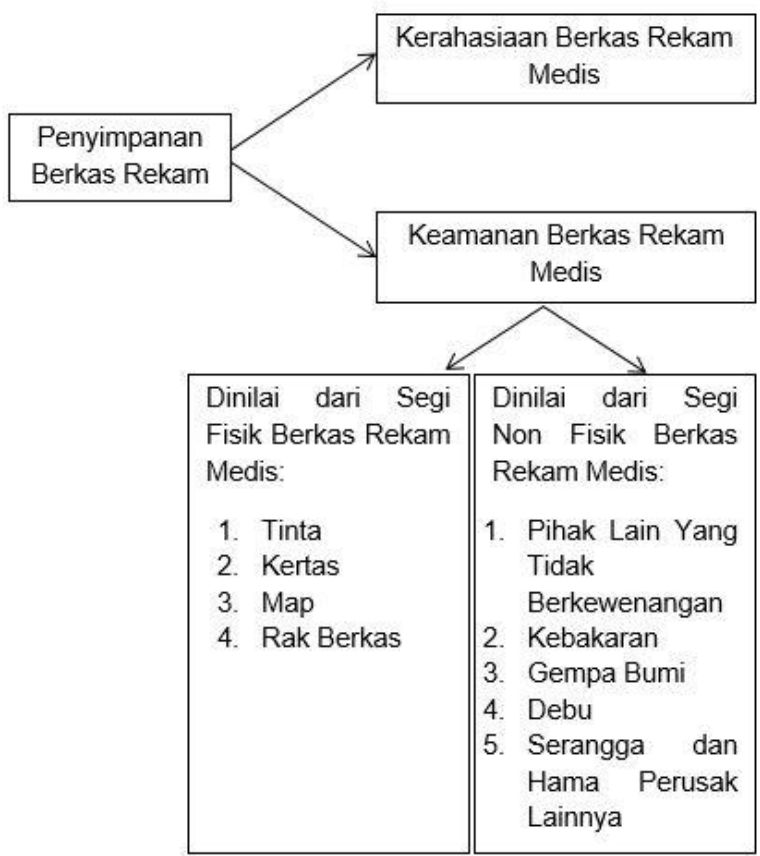

Gambar 1. Aspek kerahasiaan dan keamanan berkas rekam medis

\section{Keamanan Berkas Rekam Medis Ditinjau Dari Segi Fisik Berkas}

Keamanan berkas rekam medis ditinjau dari segi fisik berkas di Rumah Sakit Umum Daerah dr. Soehadi Prijonegoro Sragen sudah aman. Tinta yang dipilih dalam penulisan, pencatatan, dan print out pada berkas rekam medis sudah jelas, seragam, rata, dan mudah untuk dibaca. Kertas yang digunakan kertas HVS dengan ukuran A4 berat 70 gram dan tidak mudah sobek. Menurut Huffman (1994) kertas yang digunakan relatif bersih, kuat, dan memiliki mutu yang baik untuk penghapusan dan permanensi. Map berkas rekam medis yang digunakan di Rumah Sakit Umum Daerah dr. Soehadi Prijonegoro Sragen terbuat dari bahan karton. Menurut WHO (2006) bahan yang digunakan untuk membuat folder rekam medis merupakan bahan yang tebal dan tidak mudah sobek seperti kertas manila atau cardboard lain yang kuat. Bahan kertas dan map berkas rekam medis di Rumah Sakit Umum Daerah dr. Soehadi Prijonegoro Sragen sudah cukup kuat dan tidak mudah sobek. Menurut Sudra (2013), map rekam medis minimal memuat informasi sebagai berikut:
a) Identitas sarana pelayanan kesehatan
b) Tulisan "CONFIDENTIAL" atau "RAHASIA" atau keduanya
c) Nama pasien
d) Nomor rekam medis
e) Tahun kunjungan terakhir

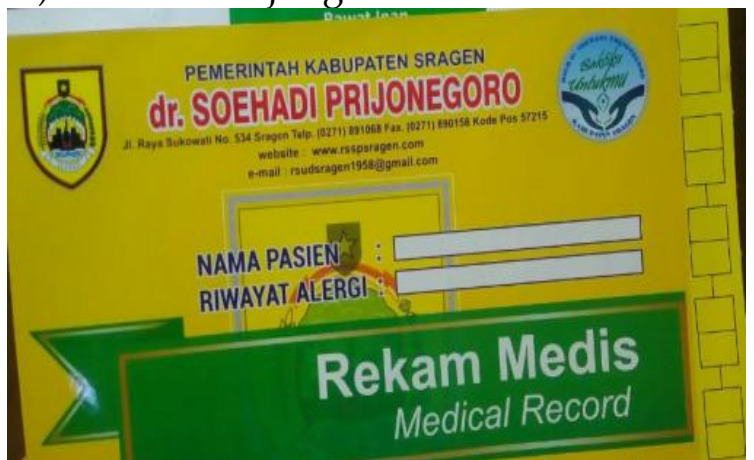

Gambar 2. Map berkas rekam medis RSUD dr. Soehadi Prijonegoro Sragen

Map berkas rekam medis yang digunakan belum terdapat kode warna. Menurut Depkes RI (1997) kode warna adalah untuk memberikan warna tertentu pada sampul, untuk mencegah keliru simpan dan memudahkan mencari map yang salah simpan.

\section{Keamanan Berkas Rekam Medis} Ditinjau Dari Segi non Fisik Berkas

Berdasarkan hasil wawancara dan observasi di Rumah Sakit Umum Daerah dr. Soehadi Prijonegoro Sragen keamanan berkas rekam medis ditinjau dari segi non fisik berkas masih belum aman. Sudah terdapat peringatan di pintu ruang penyimpanan berkas rekam medis bahwa selain petugas dilarang masuk, tetapi masih ada pihak lain yang tidak berkewenangan masuk ruang penyimpanan berkas rekam medis. Menurut Firdaus (2012) hanya petugas 
rekam medis dan petugas yang berkepentingan yang diijinkan masuk ruang penyimpanan rekam medis. Ruang penyimpanan berkas rekam medis dijadikan satu dengan bagian assembling, klaim BPJS, dan indeks. Menurut Wursanto (1991) ruangan penyimpanan arsip sebaiknya terpisah dari ruangan kantor lain untuk menjaga keamanan arsip-arsip tersebu mengingat bahwa arsip tersebut sifatnya rahasia, mengurangi lalu lintas pegawai lainnya, dan menghindari pegawai lain memasuki ruangan sehingga pencurian arsip dapat dihindari.

Keamanan berkas rekam medis dari bencana kebakaran sudah terlindungi. Sudah terdapat alat pemadam kebakaran atau APAR (Alat Pemadam Api Ringan) dan alat pendeteksi api atau asap (fire smoke detector), selain itu juga rutin dilakukan pengecekan sekring listrik di ruang penyimpanan berkas rekam medis.

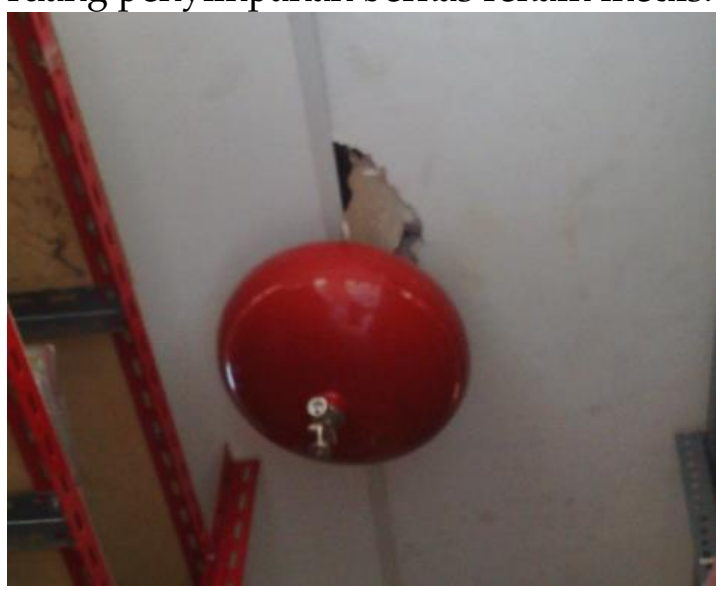

Gambar 3. Alat pendeteksi asap

Selain itu terdapat peraturan dilarang merokok di ruang penyimpanan bekas rekam medis di Rumah Sakit Umum Daerah dr. Soehadi Prijonegoro Sragen, sehingga ruang penyimpanan berkas rekam medis bersih dari puntung rokok. Menurut Sugiarto (2015) ruang penyimpanan arsip harus selalu bersih dari puntung rokok. Bangunan ruang penyimpanan berkas rekam medis terbuat dari bahan beton. Menurut Widjanarko (2006) bangunan yang tahan gempa bangunan gedung dibuat dengan menggunkan sistem struktur rangka sederhana dengan pengisi baik rangka yang dibuat dari bahan kayu maupun beton bertulang dengan dinding pengisi dari bahan bata merah atau batako. Saat penelitian ini dilaksanakan struktur bangunan masih baru tapi sudah retak.

Pada berkas rekam medis masih ditemukan debu. Hal tersebut dikarenakan kurangnya pemeliharaan kebersihan seperti penyedotan debu di ruang penyimpanan berkas rekam medis. Menurut Sugiarto (2015) ruang penyimpanan arsip harus selalu bersih dari debu. Debu dan kotoran yang dibiarkan tinggal di atas permukaan kertas, lama kelamaan akan sulit untuk dihilangkan, sehingga warna kertas akan berubah dan menimbulkan noda atau bercak serta mengaburkan tulisan.

Terkati pengendalian serangga yang dapat merusak fisik berkas, tidak ada penyemprotan racun serangga di ruang penyimpanan berkas. Menurut Sugiarto (2015) serangga berbahaya bagi arsip dan merupakan masalah yang pelik di negara tropis. Serangga tersebut biasanya membuat sarang di antara lembar-lembar arsip. Setiap enam bulan ruangan hendaknya disemprot dengan racun serangga seperti DDT, pyrethrum. Tetapi jangan sampai mengenai barangbarang arsip. Walaupun ruang penyimpanan berkas rekam medis sudah tertutup dengan baik, tetapi masih sering ditemukan bangkai tikus. Tidak ada pencegahan dalam hal ini.

\section{Kerahasiaan Berkas Rekam Medis}

Berdasarkan hasil wawancara dan observasi dengan petugas rekam medis di Rumah Sakit Umum Daerah dr. Soehadi Prijonegoro Sragen, kerahasiaan rekam medis belum terjaga dengan baik. Sudah terdapat petugas distribusi, tetapi petugas distribusi hanya mengantarkan berkas rekam medis ke poliklinik-poliklinik tujuan awal pasien akan melakukan pemeriksaan, sedangkan pasien yang akan konsultasi ke poliklinik lain atau akan melanjutkan pemeriksaan di fasilitas penunjang berkas rekam medisnya dibawa sendiri oleh pasien tersebut.

Menurut Hatta (2010) rekam medis digunakan sebagai salah satu dokumentasi keadaan pasien dan isi rekam medis merupakan rahasia kedokteran yang harus dijaga kerahasiaannya oleh setiap tenaga kesehatan. Pimpinan sarana kesehatan 
bertanggung jawab atas hilang, rusak, pemalsuan dan atau penggunaan oleh orang atau badan yang tidak berhak terhadap rekam medis. Seharusnya berkas rekam medis tidak boleh dibawa oleh pasien melainkan harus dibawa sendiri oleh petugas distribusi untuk diserahkan ke poliklinik, hal ini untuk menghindari rekam medis hilang atau terbawa oleh pasien.

\section{SIMPULAN DAN SARAN}

Dari penelitian ini dapat disimpulkan:

1. Keamanan berkas rekam medis ditinjau dari faktor internal, semua komponen sudah aman yaitu tinta, kertas, dan map.

2. Keamanan berkas rekam medis ditinjau dari faktor eksternal, semua komponen belum aman yaitu pihak lain yang tidak berkewenangan, gempa bumi, debu, serta serangga dan hama perusak lainnya.

3. Kerahasiaan berkas rekam medis belum terjaga dengan baik karena pasien membawa sendiri berkas rekam medisnya bila akan melanjutkan konsultasi ke poliklinik lain atau melanjutkan pemeriksaan di fasilitas penunjang.

Peneliti menyarankan agar aspek keamanaan dan kerahasiaan berkas rekam medis dapat terjaga:

1. Sebaiknya ruang penyimpanan berkas rekam medis terpisah dari ruangan lain. Pihak lain yang tidak berkepentingan tidak boleh masuk ruang penyimpanan berkas rekam medis.

2. Sebaiknya dilakukan pemeliharaan kebersihan di ruang penyimpanan berkas rekam medis dengan cara penyedotan debu dan menggunakan kemoceng untuk membersihkan kotoran tikus yang ada di berkas rekam medis. Selain itu, sebaiknya dilakukan penyemprotan racun serangga pada ruang penyimpanan berkas rekam medis secara periodik selama enam bulan sekali dan memasang alat yang dapat mencegah masuknya serangga dan tikus. Serta menjaga kebersihan lingkungan, sehingga tidak terjadi penumpukan sampah dan sisa makanan.

3. Sebaiknya berkas rekam medis pasien yang konsultasi ke poliklinik lain atau ingin melakukan pemeriksaan lanjutan di fasilitas penunjang diantarkan oleh petugas distribusi. Pasien tidak boleh membawa berkas rekam medisnya sendiri.

\section{DAFTAR PUSTAKA}

Depkes RI. (1997). Pengelolaan Rekam Medis Rumah Sakit di Indonesia. Jakarta: Direktorat Jendral Pelayanan Medis.

Depkes RI. (2008). Permenkes RI No.269/MENKES/PER/III/2008 tentang rekam medis. www.depkes.go.id. Diakses tanggal 5 Desember 2016.

Firdaus, S.U. (2012). Rekam Medik Dalam Sorotan Hukum Dan Etika. Surakarta: LPP UNS dan UNS Press.

Hatta, G. R. (2010). Manajemen Informasi Kesehatan di Sarana Pelayanan Kesehatan. Jakarta: UI Press.

Huffman, E.K. (1994). Health Information Management. Illionis: Physicians.

Rustiyanto, E. (2009). Etika Profesi Perekam Medis dan Informasi Kesehatan. Yogyakarta: Graha Ilmu.

Sudra, R. I. (2013). Statistik Rumah Sakit. Tangerang Selatan: Graha Ilmu.

Sugiarto, A dan Wahyuno, T. (2015). Manajemen Kearsipan Moderin. Yogyakarta: Gava Media.

WHO (2006). World Health Statistics 2006. Geneva: WHO Press.

Widjanarko, Agoes. (2006). Pedoman Teknis Rumah Dan Bangunan Gedung Tahan Gempa. Jakarta: Direktur Jendral Cipta Karya.

Wursanto, IG. (1991). Kearsipan I. Yogyakarta: Kanisius. 